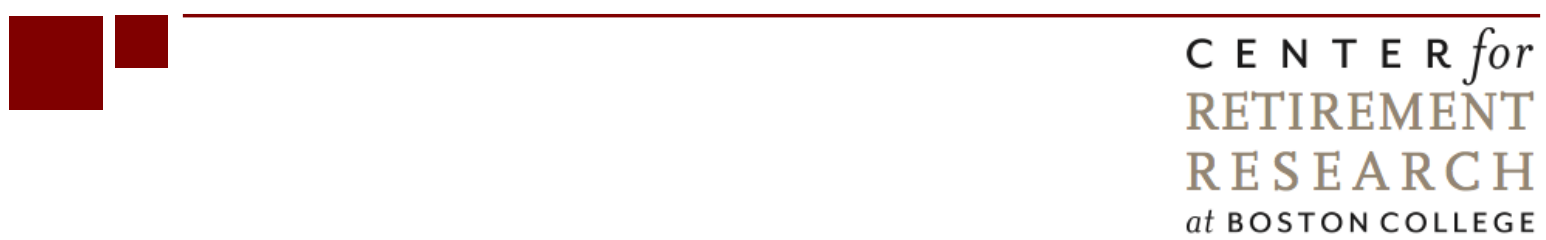

\title{
HOW IMPORTANT IS ASSET ALLOCATION TO FINANCIAL SECURITY IN RETIREMENT?
}

\author{
Alicia H. Munnell, Natalia Sergeyevna Orlova, and Anthony Webb
}

CRR WP 2012-13

Date Released: April 2012

\author{
Center for Retirement Research at Boston College \\ Hovey House \\ 140 Commonwealth Avenue \\ Chestnut Hill, MA 02467
}

Tel: 617-552-1762 Fax: 617-552-0191

http://crr.bc.edu

\begin{abstract}
All of the authors are with the Center for Retirement Research at Boston College (CRR). Alicia H. Munnell is the director and the Peter F. Drucker Professor of Management Sciences at Boston College’s Carroll School of Management. Natalia Sergeyevna Orlova is a research associate. Anthony Webb is a research economist. The opinions and conclusions expressed are solely those of the authors and do not represent the views of Boston College.

(C) 2012, Alicia H. Munnell, Natalia Sergeyevna Orlova, and Anthony Webb. All rights reserved. Short sections of text, not to exceed two paragraphs, may be quoted without explicit permission provided that full credit, including (C) notice, is given to the source.
\end{abstract}




\title{
About the Center for Retirement Research
}

The Center for Retirement Research at Boston College, part of a consortium that includes parallel centers at the University of Michigan and the National Bureau of Economic Research, was established in 1998 through a grant from the Social Security Administration. The Center's mission is to produce first-class research and forge a strong link between the academic community and decision makers in the public and private sectors around an issue of critical importance to the nation's future. To achieve this mission, the Center sponsors a wide variety of research projects, transmits new findings to a broad audience, trains new scholars, and broadens access to valuable data sources.

\author{
Center for Retirement Research at Boston College \\ Hovey House \\ 140 Commonwealth Avenue \\ Chestnut Hill, MA 02467 \\ phone: 617-552-1762 fax: 617-552-0191 \\ e-mail: crr@bc.edu \\ crr.bc.edu
}

Affiliated Institutions:

The Brookings Institution

Massachusetts Institute of Technology

Syracuse University

Urban Institute 


\begin{abstract}
Financial advice tends to focus on financial assets, but other levers may be more important for most households. This paper proceeds in three stages. The first section reports a simple Excel spreadsheet exercise that provides a stylized example of the tradeoff between returns and time spent in the labor force. The second section uses data from the Health and Retirement Study (HRS) on pre-retirees aged 51-64 to see how the gap between retirement needs and retirement resources is affected by working longer, taking out a reverse mortgage, controlling spending, and shifting all assets to equities with no risk. The third section uses a simple dynamic programming model to calculate a risk-adjusted measure of the value for the average household of moving from a typical conservative portfolio to an optimal portfolio. The answer from all three exercises is the same: the focus on asset allocation is misplaced.
\end{abstract}




\section{Introduction}

The motivation for this paper is the concern that financial advice - the topic of this conference - tends to focus on financial assets, applying tools that give prominence to the asset allocation decision. But most people have little financial wealth, and financial tools are often silent on the levers that will have a much larger effect on retirement security for the majority of Americans. These levers include delaying retirement, tapping housing equity through a reverse mortgage, and controlling spending. Moreover, even for many with substantial assets, these nonfinancial levers may be as powerful as asset allocation in attaining retirement security.

This paper proceeds in three stages. The first section reports a simple Excel spreadsheet exercise that provides a stylized example of the tradeoff between returns and time spent in the labor force. The second section uses data from the Health and Retirement Study (HRS) on preretirees aged 51-64 to see how the gap between retirement needs and retirement resources is affected by working longer, taking out a reverse mortgage, controlling spending, and shifting all assets to equities with no risk. The third section uses a simple dynamic programming model to calculate a risk-adjusted measure of the value for the average household of moving from a typical conservative portfolio to an optimal portfolio.

The answer from all three exercises is the same. The focus on asset allocation is misplaced. Households have much more potent levers for achieving retirement security.

\section{A Simple Model}

This simple model estimates what percent of earnings individuals must save to ensure a financially secure retirement, depending on when they start saving, when they retire, and how they invest their retirement savings. It shows that the age at which one begins to save and the age at which one retires are pivotal decisions in determining the required saving rate and can make the difference between a secure or insecure retirement. These factors dominate the impact of asset allocation.

The exercise uses replacement rates - the ratio of retirement income to earnings before retirement - to gauge the extent to which older people can maintain their pre-retirement levels of 
consumption once they stop working. ${ }^{1}$ People clearly need less than their full pre-retirement earnings to maintain their standard of living once they stop working. First, they pay less tax. They no longer pay Social Security and Medicare payroll tax, and they pay lower federal income tax because - at most - only a portion of their Social Security benefits are taxable. ${ }^{2}$ Second, they no longer need to save for retirement. Finally, most households pay off their mortgage before they retire, or soon thereafter.

The RETIRE Project at Georgia State University has been calculating required replacement rates for decades. ${ }^{3}$ As of 2008, the Project estimated that households with earnings of $\$ 50,000$ and over needed about 80 percent of pre-retirement earnings to maintain the same level of consumption (see Table 1). Households earning less needed more, because they generally save very little for retirement and pay much less tax while working.

The amount that individuals would have to save to end up with an 80-percent replacement rate depends on a number of factors.

- Earnings level. The lower the earnings, the greater the portion provided by Social Security and the less that the individual would have to save on his own.

- Rate of return. The higher the rate of return, the lower the required saving rate.

- Age when savings begins. The earlier the individual starts saving, the lower the required rate for any given retirement age.

- Age of retirement. The later the individual retires, the lower the required saving rate. The Social Security Trustees publish the percent of earnings that Social Security will replace at age 65 and at the eventual Full Retirement Age of 67 for low, medium, high, and

\footnotetext{
${ }^{1}$ Technically, people are interested in smoothing marginal utility, not consumption. If additional leisure enables the household to attain the same marginal utility at lower levels of consumption, it may be optimal to accept lower consumption after retirement. This is one explanation for what the literature calls the 'retirement-consumption puzzle' - namely, the fact that consumption appears to drop as people retire. See Bernheim, Skinner and Weinberg (2001), Banks, Blundell and Tanner (1998), and Hurd and Rohwedder (2003).

${ }^{2}$ The taxation treatment of Social Security benefits is as follows. First, the household calculates its 'combined income.' Combined income is regular taxable income plus 50 percent of Social Security benefits. The taxable amount of Social Security benefits is the minimum of three tests: (1) 50 percent of combined income over the first threshold (\$25,000 for singles and \$32,000 for married couples) plus 35 percent of combined income over the second threshold (\$34,000 for singles and $\$ 44,000$ for married couples); (2) 50 percent of benefits plus 85 percent of combined income over the second threshold; or (3) 85 percent of benefits (Internal Revenue Service 2012).

${ }^{3}$ For an array of pre-retirement earnings levels, they calculate federal, state, and local income taxes and Social Security taxes before and after retirement. They also use the Bureau of Labor Statistics Consumer Expenditure Survey to estimate consumer savings and expenditures for different earnings levels. Further details are reported in Palmer (2008).
} 
maximum earners (see Table 2). ${ }^{4}$ Replacement rates for other ages from 62 to 70 were calculated using the appropriate actuarial adjustment for early retirement or delayed retirement credit for later retirement. ${ }^{5}$ Subtracting Social Security’s replacement rate from 80 percent determines the percent of earnings that must be replaced by individual savings.

The final issue is to determine the income drawn from retirement savings. The calculations assume the '4-percent rule.' That is, an individual who retires at age 65 annually withdraws 4 percent of savings attained in that year. Those who retire earlier would withdraw somewhat less and those who retire later somewhat more. ${ }^{6}$ Another option would be to purchase an inflation-indexed annuity, which yields very similar results.

The required saving rate will depend on the real return earned on accumulated assets, when the individual begins saving, and when the individual retires. ${ }^{7}$ The real rates of return are assumed to range from 1 percent to 7 percent; all individuals are assumed to be age 25 in 2010 and start saving at ages 25,35 , or 45 , and retirement ages are assumed to range from 62 to $70 .^{8} \mathrm{~A}$ wage growth assumption of 1.2 percent above inflation is used. ${ }^{9}$

An example will illustrate. Consider an individual who is 25 in 2010, earns Social Security’s medium earnings of \$43,000, and retires at the Full Retirement Age of 67 in 2052. Under current law, Social Security will replace 41 percent of this individual's final inflationadjusted earnings of $\$ 71,000$; so the individual has to save enough to replace 39 percent (80 percent minus 41 percent), or about $\$ 27,700$. With the 4-percent rule, the individual needs just

\footnotetext{
${ }^{4}$ United States Social Security Administration (2008).

${ }^{5}$ The low earner has career average earnings equal to about 45 percent of the national average wage index (AWI). The medium earner has career average earnings equal to about 100 percent of the AWI. The high earner has career average earnings equal to about 160 percent of the AWI. The average wage index in 2010 was $\$ 43,084$ and maximum taxable earnings were $\$ 106,800$. Thus, the low-wage worker would earn $\$ 19,388$ and the high-wage worker would earn $\$ 68,934$.

${ }^{6}$ Bengen (1994) shows that households adopting this strategy and who invest in a mixed stock-bond portfolio face a relatively low risk of outliving their wealth. Although sub-optimal, we assume that the appropriate percentage drawdown rate is not affected by realized returns during the accumulation phase (i.e. that realized returns do not provide information about the distribution of prospective returns).

${ }^{7}$ As most saving in the United States is done through employer-sponsored plans - primarily 401(k)s - the required saving rate should be viewed as the combined employer-employee contribution rate.

${ }^{8}$ The calculation abstracts from investment risk; in reality, an expected 7-percent real return can only be earned at the cost of assuming very considerable risk. It also abstracts from the notion of optimal saving. Indeed, for households that are middle-aged and have yet to start saving for retirement, the optimal strategy will likely be not only to delay retirement but also to cut the target level of post-retirement consumption (Kotlikoff 2008).

${ }^{9}$ This assumption is used by the United States Social Security Administration (2011) for the economy as a whole. Individual workers may experience more rapid increases as they gain seniority in jobs. More rapid wage growth will increase the required saving rate, all else equal.
} 
under $\$ 660,000$ in 2052. If the individual starts saving at 35 and earns a real return of 4 percent, he will need to save 18 percent of earnings each year.

The required saving rates for the medium earner, assuming a rate of return of 4 percent are presented in Table 3. Two messages stand out. First, starting to save at age 25, rather than age 45, cuts the required saving rate by about two thirds. Second, delaying retirement from age 62 to age 70 also reduces the required saving rate by about two thirds. As a result, the individual who starts at 25 and retires at 70 needs to save only 7 percent of earnings to achieve an 80percent replacement rate at retirement, one tenth of the rate required of an individual who starts at 45 and retires at 62 - an impossible 65 percent. ${ }^{10}$ But note that even that individual who starts at 45 has a plausible 18 percent required saving rate if he postpones retirement to age 70 .

Retiring later is an extremely powerful lever for several reasons. First, because Social Security monthly benefits are actuarially adjusted, they are over 75 percent higher at age 70 than age 62. As a result, they replace a much larger share of pre-retirement earnings at later ages 28.6 percent at 62 and 51.5 percent at 70 in our example - reducing the amount required from savings. Second, by postponing retirement people have additional years to contribute to their 401(k) and allow their balances to grow. Finally, a later retirement age means that people have fewer years to support themselves on their accumulated retirement assets. This simple model highlights the impact of delayed retirement on the required saving rates.

Up to now, the rate of return on assets has been held at 4 percent. Table 4 shows the impact of lower and higher rates of return for individuals who start at age 35. The 2-percent return is slightly less than the long-run rate of return on intermediate-term government bonds and the 6-percent return is slightly less than the long-run rate of return on large capitalization stocks. ${ }^{11}$ While higher returns require smaller contribution rates, they also come with increased risk. Even ignoring risk, the required saving differentials are less than those associated with ages for starting to save and the age of retirement. In fact, an individual can offset the impact of a 2percent return instead of a 6-percent return by retiring at 67 instead of 62 .

\footnotetext{
${ }^{10}$ A more sophisticated analysis would adjust the target replacement rate. That is, if an individual were indeed saving 48 percent of earnings, he would be living on 52 percent. The 80-percent target would no longer be appropriate.

${ }^{11}$ Ibbotson (2010) data show that, over the period 1926-2010, real stock returns have averaged 6.5 percent and the real return on the 10 -year Treasury was 2.4 percent.
} 
In summary, starting early and working longer are far more effective levers for gaining a secure retirement than earning a higher return. This strategy of saving for a longer period of time is especially effective given the greater risk that comes from attempting to earn that higher return. And the further along people are in their career, the more effective working a few years longer becomes. The next section moves from hypothetical individuals to examining the effects of alternative strategies on actual households in the HRS.

\section{Retirement Income Targets and Resources for HRS Households}

The Health and Retirement Study (HRS) is a nationally representative panel of older American households, which began in 1992 by interviewing about 12,650 individuals from about 7,600 households ages 51-61 and their spouses (regardless of age). ${ }^{12}$ The survey has been readministered every two years since 1992. Over time, other cohorts have been added to the survey, substantially increasing the sample size. War Babies (born between 1942 and 1947) were added in 1998; Early Boomers (born between 1948 and 1953) were added in 2004; and Mid Boomers (born between 1954 and 1959) were added in 2010. Like the original sample, these three additional cohorts are interviewed every two years.

The sample for this analysis is derived by transforming the RAND HRS data into households and focusing on those households with a working head under age 65. All individuals who reported being single are defined as household heads. For couples, the male is identified as the head. In case of same sex couples, the higher earning spouse is the head or the older one if earnings were equivalent.

The sample is used in cross section, so households for which complete data are available may be observed repeatedly until they reach age 64 . As a result, the sample begins with 21,423 observations of households with heads under age 65 at waves 5 to 9 of the HRS (2000 to 2008). From that total, 7,193 observations were dropped because the household head was not working and a further 1,604 observations were dropped because the data were incomplete or inconsistent.

\footnotetext{
${ }^{12}$ The HRS is conducted by the Institute for Social Research (ISR) at the University of Michigan and is made possible by funding from the National Institute on Aging. More information is available at the ISR website: http://hrsonline.isr.umich.edu/.
} 
These deletions produced a final sample of 12,626 observations. ${ }^{13}$ Table 5 compares our sample with age-eligible households. The sample is of somewhat higher socioeconomic status than the population as a whole, because working households tend to have more education and better health than those not working. ${ }^{14}$

The goal is to create, for each household observation, target replacement rates and projected replacement rates for each age from 60 to 70 . Once constructed, the levers can be applied to test their relative power in helping households achieve a secure retirement income.

\section{Target Replacement Rates}

Once the sample is constructed, the next step is to calculate a target replacement rate that will enable the household, at each retirement age from 60 to 70, to maintain its current standard of living, covering both pre-retirement consumption and making any required mortgage payments.

\section{Consumption}

The original plan was to measure each household's current consumption using Consumption and Activities Mail Survey (CAMS) data and to impute consumption data for those households not participating in the CAMS. Initial tabulations, however, showed low-income households consuming substantially in excess of their income, while high-income households were spending implausibly small percentages of their income on consumption. An econometric model in which consumption was the dependent variable and income the explanatory variable produced implausibly small estimates of the marginal propensity to consume, even if one were to adjust for taxes and 401(k) contributions. So the initial plan was aborted in favor of using the replacement rates from Georgia State University’s 2008 RETIRE Project Report discussed above.

\footnotetext{
${ }^{13}$ The primary reason for dropping observations was that the head reported working, but having zero earnings. We retained the observation if the head reported that he was in the same job as in the previous wave, and reported nonzero earnings in the previous wave.

${ }^{14}$ Wealth levels are similar to those reported in Moore and Mitchell (2000), after making allowance for inflation.
} 


\section{Mortgage payments}

CAMS is the only source of households' mortgage payments in the HRS. Although HRS households are asked about their mortgage balance outstanding, they are not asked about their remaining mortgage term. The remaining mortgage term was calculated from data on balances and annual payments assuming a 6-percent nominal interest rate, which approximates the average interest rate on a 30-year fixed mortgage during the survey period. The term was set to one year if the reported annual payment was greater than debt and to 30 years if the ratio of payments to outstanding balance was less than or equal to the interest, or if the term was greater than 30 years.

The next step was to estimate mortgage payments and mortgage term for people not included in CAMS. Again, an attempt was made to impute mortgage payments based on data for the CAMS subsample. Initial tabulations showed that the ratio of mortgage payments to debt was tightly clustered around the median of 0.12, implying a median remaining mortgage term of about 12 years. An econometric model, in which the ratio of mortgage payments to mortgage balance outstanding was the dependent variable and explanatory variables included house value, age, and socioeconomic characteristics, produced statistically insignificant coefficients. Therefore, the assumption was made that non-CAMS households all had a remaining term of 12 years.

\section{Income Targets}

Georgia State University’s RETIRE Project provides four sets of retirement income replacement rates that vary by marital status, age, and labor force participation status. Each set of replacement rates is for incomes of $\$ 20,000$ to $\$ 90,000$ in increments of $\$ 10,000$. HRS households were assigned target replacement rates based on these factors. The assumption was that households were aiming to replace the relevant percentage of the average of the last 10 years' earnings. $^{15}$

The RETIRE report does not explicitly model mortgage debt, so the targets need to be adjusted to reflect our projection that a significant proportion of the sample will have either repaid their mortgage by retirement or be able to repay all or part of the balance outstanding at

\footnotetext{
${ }^{15}$ The 10-year period refers to the decade before the observation, not the 10 years prior to retirement.
} 
that time by drawing on financial assets. The adjustment involved subtracting annual mortgage payments reported by respondents from their target retirement incomes, then adding annual mortgage payments multiplied by the ratio of remaining mortgage debt (mortgage debt less financial assets) to initial debt at retirement. The adjusted targets were calculated for each household observation for ages 60 through 70.

\section{Projected Retirement Replacement Rates}

Armed with retirement income targets, the next step is to calculate the projected retirement replacement rate that the household will achieve if it continues on its present course, maintaining its current saving rate and asset allocation and not taking a reverse mortgage. Total income at retirement in this baseline scenario consists of Social Security, employer pensions, and income from financial assets.

\section{Social Security}

Projected Social Security benefits are calculated using the HRS Social Security earnings records, available to qualified researchers on a restricted basis. When the Social Security earnings records are not available, earnings histories were imputed using current earnings, earnings at the first HRS interview, and final earnings in previous job. ${ }^{16}$ Wages between the age the household is observed and the retirement age are projected using Social Security's Average Wage Index (United States Social Security Administration 2011). The entire wage history is then indexed by the Average Wage Index, and the highest 35 years of indexed wages are used to calculate the Average Indexed Monthly Earnings (AIME). The benefit formula is then applied to the AIME to derive the individual's Primary Insurance Amount.

\footnotetext{
${ }^{16}$ When the Social Security earnings records are not available, the procedure followed Gustman and Steinmeier (2001) and estimate earnings histories based on HRS data on previous jobs and wages, using the estimated returns to tenure from Anderson, Gustman, and Steinmeier (1999).
} 


\section{Pension Income}

Pension income is based on the 1998 and 2004 HRS imputed data for employersponsored pension plan wealth in current jobs. ${ }^{17}$ Households in waves 7 through 9 (2004, 2006, and 2008) were assigned pensions from the 2004 data set; households in waves 5 and 6 (2000 and 2002) from the 1998 data. The data sets differ slightly. The 2004 data set includes values for retirement ages 60, 62, 65 and 70. For the 1998 data set, pension values were available only for ages 60, 62, and 65. The 2004 data set discounts defined benefit pension wealth to the survey year, while the 1998 data set projects defined benefit wealth to the retirement age. The 1998 values are extrapolated to age 70 based on the average increase in retirement wealth from 65 to 70 in the 2004 data. For both data sets, values for ages 61, 63, 64, and 66 through 69 are interpolated based on the reported numbers.

Defined benefit pension wealth is converted into pension income using the interest and inflation rate assumptions embedded in the pension wealth calculations. ${ }^{18}$ In the case of defined contribution pension wealth, the starting point is the account balance. Balances then grow as participants contribute 6 percent of salary, receive a 50-percent employer match, and earn a 4.6 percent real return until retirement. People who started their jobs after 1998 (waves 5 and 6) or 2004 (waves 7, 8 and 9) are assumed to receive no pension benefits on their new job. The conversion of defined contribution wealth to income is discussed in the next section on financial assets.

\section{Financial Assets}

Household financial wealth invested in stocks, bonds, and short-term deposits is assumed to earn returns of 6.5, 3.0 and 1.0 percent, respectively, from the date of the interview until retirement. These rates approximate the long-run average rates of return on each of the three asset classes. Importantly, these assumptions are used throughout for projecting asset returns rather than incorporating any actual fluctuations. The objective is to assess whether households

\footnotetext{
${ }^{17}$ Participants in the HRS are asked about projected benefits from employer pensions. The HRS also obtains pension plan data from participants' employers. The HRS pension data collected from participants suffers from high levels of non-response and mis-reporting of pension type. We considered using data that the HRS has collected from respondents' employers. But these data are only available for about two thirds of participants.

${ }^{18}$ The interest rate assumption is irrelevant, provided that the same assumption is used to both calculate pension wealth from respondents' estimates of their pension income, and then recover pension income from pension wealth.
} 
are on track to meet their replacement rate targets, not whether they actually succeeded in meeting them.

At retirement, the household is assumed to purchase a nominal joint or single life annuity with all its financial assets, including 401(k) and IRA balances. Currently, annuity rates are extremely low, reflecting depressed interest rates. The objective of this exercise is to calculate financial preparedness for retirement, given the beliefs of respondents at the date of the HRS interviews. Therefore, the assumed annuity rates are based on a 5.1 percent 10-year Treasury Bond interest rate, projected mortality improvements based on Social Security Administration cohort mortality tables, and current expense loads. ${ }^{19}$ At this point, target and projected replacement rates are available for each household observation for ages 60 through 70 .

\section{Applying the Levers}

The difference between the target replacement rates and projected replacement rates measures the extent to which each household's needs fall short of resources, and provides the baseline against which to assess the respective contributions of four possible interventions to bridge the gap. These interventions may not be utility maximizing; the best strategy may be to accept lower consumption, both now, and in retirement. But the objective is not to identify an optimal strategy, but to calculate the effectiveness of each of the interventions at bridging the gap between post-retirement needs and resources.

\section{Reverse Mortgage Income}

The first intervention is to have the household take out a reverse mortgage. Reverse mortgage income was calculated as follows. For homeowners without a mortgage, the household takes the maximum available loan, given the age of the younger spouse and the house value, and exercises the lifetime income option. The proceeds from that option are based on January 2012 interest rates and typical closing costs and expenses. For homeowners with a mortgage, the household uses its financial assets to clear its mortgage debt at retirement. If financial assets are insufficient to clear the mortgage, the household takes part of its reverse mortgage in the form of a lump sum, reducing the amount payable under the reverse mortgage

\footnotetext{
${ }^{19}$ To simplify the calculations, the spouse is assumed to be the same age as the head of the household.
} 
lifetime income option. These reverse mortgage calculations produced a new set of projected retirement income for those households who own a home.

\section{Delay Retirement}

The second intervention is to postpone retirement and the claiming of Social Security benefits. Postponing retirement gives the household the opportunity to make additional 401(k) contributions, earn additional returns on its investments, and increase its Social Security benefits, and also reduces the period that accumulated assets must finance. The baseline results provide the required information of the effect of later retirement on the gap because they present targets and projected replacement rates for each age.

\section{Asset Allocation}

For this portion of the project, the asset allocation exercise was simply to allow each household to invest all its assets in equities, earning a 6.5 percent real return, and face no costs associated with the increased risk. Investing 100 percent in 'riskless equities' will have an impact on both projected wealth at retirement and the amount that the household can consume during the course of retirement. The notion is that if asset allocation does not dominate the other levers with 'riskless equities,' it would never dominate.

\section{Control Spending}

The fourth intervention is to control spending, using the money saved to increase savings. This intervention has two effects. First, the additional 401(k) contributions increase the household's retirement wealth and retirement income. Second, it reduces post-retirement needs, by reducing the level of pre-retirement consumption that the household must maintain in retirement. For this exercise, the household increases its 401(k) contribution by five percentage points, which produces a commensurate decline in the replacement rate target.

\section{Results}

The results of the interventions for the sample as a whole are shown in Table 6. Under the base case, 74 percent of households fall short of their target at age 62. If households work to 
age 67, Social Security’s ultimate Full Retirement Age, that share drops to 46 percent. If households who own a home take out a reverse mortgage, the share falling short reaches 46 percent at age 65.5. If households cut their spending by five percentage points - thereby increasing their saving and lowering their targets - the percent at risk falls to 46 percent at age 66. If households invest 100 percent of their assets in 'riskless equities' from the date first observed until they retire, they reach the 46-percent figure six months earlier than the base case at age 66.5. In other words, working six months longer - from 66.5 to 67 - produces the same outcome as having all assets invested in 'riskless equities.' As shown in the following section, taking risk into consideration shifts the balance in favor of working longer. The fact that asset allocation has only a minor impact is not surprising given that most households do not have significant financial wealth (see Table 7).

A second set of results focuses just on the top decile of the wealth distribution, which includes households with more than $\$ 500,000$ of financial wealth. Since these households are wealthier, a lower percentage of households fall short at 62 even in the base case - 39 percent for the top decile versus 74 percent for the population as a whole (see Table 8). If top-decile households worked to 67 , the share falling short drops to 17 percent. If these households take out a reverse mortgage, the 17-percent threshold is reached at age 66. The relative impact of a reverse mortgage is smaller for the wealthy because their home is a much smaller component of their total wealth. If households control their spending, the percent at risk falls to 17 percent at age 66. Finally, investing all assets in 'riskless equities' allows the top decile to reach the 17percent threshold at about 66.5. Thus, even for the top decile, asset allocation is not a particularly powerful lever.

\section{Dynamic Modeling}

The final exercise uses dynamic programming techniques to calculate a risk-adjusted measure of the potential gain from portfolio rebalancing. The analysis focuses first on the typical household approaching retirement and then on a household that is typical of those in the top financial wealth decile.

The typical household is aged 57, has a household income of \$62,600 and financial wealth of $\$ 60,500$. The household's portfolio is held in tax-deferred accounts, and the portfolio 
allocation is 36 percent in stocks, 16 percent in bonds, and 50 percent in cash. ${ }^{20}$ The assumption is that stock returns are independent and identically distributed (i.i.d.) with a mean of 6.5 percent and a standard deviation of 20 percent, the average for the period 1926-2010. Bonds and shortterm deposits are both assumed to be risk free, with real returns of 3 and 1 percent, respectively. $^{21}$

Following Scholz, Seshadri, and Surachai (2006), earnings follow an autoregressive process of order one $(\operatorname{AR}(1)){ }^{22}$ The retirement age is 66, and the household's $401(\mathrm{k})$ deferral is nine percent of salary. The household will receive Social Security benefits of $\$ 20,800$ a year, the median for this birth cohort. ${ }^{23}$ Earnings before retirement are subject to federal income and payroll taxes, and withdrawals from tax-deferred accounts and Social Security benefits are subject to federal income taxation after retirement. Prior to retirement, the household's consumption equals labor market earnings, minus taxes and 401(k) deferrals.

The first step is to calculate an optimal decumulation of financial assets in retirement from the typical portfolio allocation described above. For this calculation, the household is assumed to have a constant relative risk aversion utility function over consumption in excess of the federal poverty guideline. The household has a coefficient of relative risk aversion (CRRA) of 5 or 2 and population average mortality for the 1950 birth cohort. ${ }^{24}$ The rate of time preference is assumed to be 3 percent.

The second step is to have the household switch from the typical portfolio described above to an optimal portfolio, which varies with age. The goal is to calculate the dollar amount

\footnotetext{
${ }^{20}$ Introducing both taxable and tax-deferred accounts and allowing households to choose the order in which the household draws on these accounts would greatly complicate the model without yielding any important insights.

${ }^{21}$ In a single period model, both stocks and bonds carry risk. Campbell and Viceira (2002) argue that over a long time horizon, bonds, and in particular, Treasury Inflation Protected Securities are the true risk-free asset, because they guarantee return on capital. If a long-term investor knew his consumption requirements with certainty, he could fund them by buying a portfolio of bonds of appropriate maturities. We therefore assume that corporate bonds yield a fixed three percent return, approximating the yield on corporate bonds, after deducting anticipated inflation. Our assumed real rate of return is considerably in excess of the current negative real interest rates, reflecting an assumption that short-term interest rates will eventually revert to more normal levels.

${ }^{22}$ An alternative would be to assume that the household experiences both permanent and transitory wage shocks, as in Chai, Horneff, Maurer, and Mitchell (2011).

${ }^{23}$ Given our assumption of labor income uncertainty, the household also faces some small level of uncertainty as to the amount of its Social Security benefits.

${ }^{24}$ Estimates of coefficients of risk aversion in the academic literature range between 2 and 10, depending in part on whether the estimates are derived from portfolio theory, purchases of insurance, economic experiments, or preferences over lotteries (Chetty 2003).
} 
by which the wealth of the household retaining the typical portfolio must be increased, so that the household is as well-off in expected utility terms as when it adopts the optimal allocation.

The third step is to have the household switch from the typical portfolio to one invested entirely in stocks and calculate the dollar amount, if any, by which the current wealth of a household retaining the typical portfolio must be increased, so that it is as well off in expected utility terms as when it switches to a portfolio invested exclusively in stocks.

The results for the typical household for two levels of risk aversion are reported in the upper panel of Table 9. One piece of information that helps provide some intuition behind the findings is that a large portion of the total wealth of the typical household is the present discounted value of future Social Security benefits. Since Social Security wealth is a bond-like asset, under the assumption of CRRA utility, the optimal allocation for these households involves a large share of financial wealth invested in equities (see Table 10).

Assuming a CRRA of 5, the amount required to compensate the household for retaining a typical portfolio (where 36 percent of assets are invested in equities), rather than switching to an optimal portfolio allocation (where 51 percent of assets are invested in equities), is $\$ 5,600$, or approximately the additional amount the household would earn if it delayed retirement by one month. In contrast, when the comparison is between a typical portfolio and an all-stock portfolio, the household is better off retaining the typical portfolio by approximately $\$ 3,600$, or under one month's salary. That is, an all-stock portfolio is even more sub-optimal than the typical conservative portfolio. The key message, however, is that the dollar amounts are small, suggesting that asset allocation is relatively unimportant for the typical risk-averse household. Even if the household is less risk averse (CRRA equals 2), the story is similar. In this case, as shown in Table 10, the optimal portfolio is all in stocks. The cost of retaining a typical portfolio (57 percent in equities), rather than switching to an optimal portfolio (100 percent in equities), is $\$ 25,700$, or just over four months' salary. As the optimal portfolio is 100 percent in equities, the cost of retaining a typical portfolio relative to an all-stock portfolio is also $\$ 25,700$. In short, regardless of the degree of risk aversion, asset allocation is relatively unimportant for the typical household.

The lower panel of Table 9 reports results for the household in the top decile of financial wealth. This household has income of $\$ 137,800$ and financial assets of $\$ 889,000$, 57 percent in 
stocks, 22 percent in bonds, and 21 percent in short-term deposits. Because Social Security wealth is a much smaller share of the wealth of this household, the optimal equity holdings are lower than for the typical household (see Table 10). If the household has a CRRA of 5, the cost of retaining a typical portfolio (36 percent in equities), rather than switching to an optimal portfolio (29 percent in equities), is $\$ 87,000$. Again, as in the example of the typical household, the top-decile household is better off retaining a typical portfolio rather than switching to an allstock portfolio; the benefit is $\$ 302,700$. The comparable amounts for a household with a CRRA of 2 are a cost of $\$ 20,000$ and a benefit of $\$ 11,100$. Although the amounts required as compensation are larger for the top-decile household than for the typical household, with the exception of imposing an all-stock portfolio they are still small relative to working longer.

\section{Conclusion}

Financial planning tools frequently highlight the asset allocation decision, suggesting that individuals have a lot to gain by adopting a more optimal allocation of stocks and bonds. In contrast, they are often silent on the benefits of other options, such as delaying retirement, controlling spending, or taking out a reverse mortgage. Strikingly, the typical 401(k)/IRA balance of households approaching retirement is less than $\$ 100,000$, which suggests that the net benefits of portfolio reallocation have to be modest for the typical household. Although it is possible that higher income households have more to gain.

A simple Excel exercise aimed at determining the required saving rates for individuals with different starting ages, ending ages, and asset returns showed that the difference between earning a real return of 2 percent instead of 6 percent could be offset by working five years longer. This finding suggests a minor role for asset allocation in creating a secure retirement.

The second piece of analysis moved from hypothetical individuals to examining the effects of alternative strategies on actual households in the HRS. The exercise consisted of estimating target and projected replacement rates for each household for ages 60 through 70 . The metric of interest was the percent of households falling short. The baseline results showed that working longer substantially reduced that metric. Three other levers were evaluated against working longer - tapping home equity through a reverse mortgage, controlling spending, and investing 100 percent in 'riskless equities.' The results showed that, for the typical household, 
asset allocation was unimportant. The importance of asset allocation was somewhat greater for households in the top decile, but less than one would expect.

Since the second exercise abstracted from risk, the third exercise used dynamic programming techniques to calculate a risk-adjusted measure of the potential gain from portfolio rebalancing for both the typical household and the household in the top 10 percent of the financial wealth distribution. In all but one case, the dollar amount of the cost or benefit was equal to only a few additional months of work. In other words, asset allocation was not important.

Given the relative unimportance of asset allocations, financial advisers will be of greater help to their clients if they focus on a broad array of tools - including working longer, controlling spending, and taking out a reverse mortgage. 


\section{References}

Anderson, P. M., A. L. Gustman and T. L. Steinmeier (1999). “Trends in Male Labor Force Participation and Retirement: Some Evidence on the Role of Pension and Social Security in the 1970s and 1980s.” Journal of Labor Economics, 17(4), Part 1: 757-783.

Banks, J., R. Blundell, and S. Tanner. 1998. “Is There a Retirement-Savings Puzzle?” American Economic Review, 88(4): 769-788.

Bengen, W. 1994. "Determining Withdrawal Rates Using Historical Data.” Journal of Financial Planning, 17(3): 64-73.

Bernheim, D., J. Skinner, and S. Weinberg. 2001. "What Accounts for the Variation in Retirement Wealth Among U.S. Households?” American Economic Review, 91(4): 832857.

Campbell, J.Y. and Viceira L. M. 2002. Strategic Asset Allocation: Portfolio Choice for LongTerm Investors. Oxford, UK: Oxford University Press.

Chai, J., W. Horneff, R. Maurer, and O. S. Mitchell. 2011. "Optimal Portfolio Choice Over the Life-Cycle with Flexible Work, Endogenous Retirement, and Lifetime Payouts.” Review of Finance, 15(1): 875-907.

Chetty, R. 2003. “A New Method of Estimating Risk Aversion.” NBER Working Paper 9988. Cambridge, MA: National Bureau of Economic Research.

Gustman, Alan L. and Thomas L. Steinmeier. 2001. "How Effective is Redistribution under the Social Security Benefit Formula?” Journal of Public Economics, 82(1): 1-28.

Hurd, M. and S. Rohwedder. 2003. “The Retirement-Consumption Puzzle: Anticipated and Actual Decline in Spending at Retirement.” NBER Working Paper 9586. Cambridge, MA: National Bureau of Economic Research.

Ibbotson Associates. 2010. 2010 Ibbotson Stocks, Bonds, Bills, and Inflation (SBBI) Classic Year-book. Chicago, IL: Morningstar, Inc.

Internal Revenue Service (IRS), United States Department of the Treasury. 2012. Individual Retirement Arrangements. Publication 590. Washington DC: IRS.

Kotlikoff, L. J. 2008. “Economics’ Approach to Financial Planning.” Journal of Financial Planning, 21(3): 42-52.

Moore, J. F. and O. S. Mitchell. 2000. "Projected Retirement Wealth and Savings Adequacy in the Health and Retirement Study," in O. S. Mitchell, P. B. Hammond, and A. M. Rappaport, eds., Forecasting Retirement Needs and Retirement Wealth. Philadelphia, PA: Pension Research Council Publications, pp. 68-94. 
Palmer. B. A. 2008. “2008 GSU/Aon RETIRE Project Report.” Research Report Series 08-1. Atlanta, GA: J. Mack Robinson College of Business, Georgia State University.

Scholz, J. K., A. Seshadri, and K. Surachai. 2006. “Are Americans Saving “Optimally” for Retirement?” Journal of Political Economy, 114(4): 607-43.

United States Social Security Administration. 2011. The Annual Report of the Board of Trustees of the Federal Old-Age and Survivors Insurance and Federal Disability Insurance Trust Funds. SSA-66-327. Washington, DC: Government Printing Office.

2010. The Annual Report of the Board of Trustees of the Federal Old-Age and Survivors Insurance and Federal Disability Insurance Trust Funds. SSA-57-811. Washington, DC: Government Printing Office.

2008. Early or Late Retirement? Washington, DC: Government Printing Office.

University of Michigan. Health and Retirement Study. 2000-2008. Ann Arbor, MI. 
Table 1. Percent of Pre-Retirement Salary Required to Maintain Living Standards, 2008

\begin{tabular}{lcc}
\hline Pre-retirement earnings & Two-earner couples & Single workers \\
\hline$\$ 20,000$ & $94 \%$ & $88 \%$ \\
$\$ 50,000$ & 81 & 80 \\
$\$ 90,000$ & 78 & 81 \\
\hline
\end{tabular}

Source: Palmer (2008).

Table 2. Current Law Social Security Replacement Rates, 2030 and Later

\begin{tabular}{lll}
\hline \multirow{2}{*}{ Earnings level } & \multicolumn{2}{c}{ Age } \\
\cline { 2 - 3 } & 67 & 65 \\
\hline Low & $55.2 \%$ & $48.9 \%$ \\
Medium & 40.9 & 36.3 \\
High & 33.9 & 30.0 \\
Maximum & 27.2 & 23.9 \\
\hline
\end{tabular}

Source: Social Security Administration (2010): Table F10.

Table 3. Saving Rate Required for a Medium Earner to Attain an 80-Percent Replacement Rate with a 4-Percent Rate of Return

\begin{tabular}{llll}
\hline \multirow{2}{*}{ Retire at: } & \multicolumn{3}{c}{ Start saving at: } \\
\cline { 2 - 4 } & 25 & 35 & 45 \\
\hline 62 & $22 \%$ & $35 \%$ & $65 \%$ \\
65 & 15 & 24 & 41 \\
67 & 12 & 18 & 31 \\
70 & 7 & 11 & 18 \\
\hline
\end{tabular}

Source: Authors' calculations. 
Table 4. Saving Rate Required for a Medium Earner to Attain an 80-Percent Replacement Rate with a Starting Age of 35, by Rate of Return

\begin{tabular}{lccc}
\hline \multirow{2}{*}{ Retire at: } & \multicolumn{3}{c}{ Real rate of return } \\
\cline { 2 - 4 } & 2 percent & 4 percent & 6 percent \\
\hline 62 & $46 \%$ & $35 \%$ & $26 \%$ \\
65 & 32 & 24 & 17 \\
67 & 26 & 18 & 13 \\
70 & 16 & 11 & 7 \\
\hline
\end{tabular}

Source: Authors’ calculations. 
Table 5. Comparison of Workers with All HRS Households Under Age 65

\begin{tabular}{|c|c|c|c|}
\hline \multirow[b]{2}{*}{ Age } & \multicolumn{2}{|c|}{$\begin{array}{c}\text { Working } \\
\text { (our sample) }\end{array}$} & \multirow{2}{*}{$\frac{\text { All }}{57.4}$} \\
\hline & 56.9 & $* * *$ & \\
\hline Married couple & 0.644 & $* * *$ & 0.605 \\
\hline \multicolumn{4}{|l|}{ Ethnicity: } \\
\hline Black & 0.098 & $* * *$ & 0.120 \\
\hline Hispanic & 0.078 & $* * *$ & 0.085 \\
\hline \multicolumn{4}{|l|}{ Education: } \\
\hline Less than high school & 0.094 & $* * *$ & 0.143 \\
\hline Some college & 0.602 & $* * *$ & 0.542 \\
\hline Home owner & 0.838 & $* * *$ & 0.796 \\
\hline Median house value (home owners only) & $\$ 180,000$ & $* * *$ & $\$ 171,000$ \\
\hline Has mortgage & 0.546 & $* * *$ & 0.468 \\
\hline Median mortgage balance (households with mortgages only) & $\$ 89,750$ & $* *$ & $\$ 85,500$ \\
\hline \multicolumn{4}{|l|}{ Pension: } \\
\hline DB or both & 0.286 & $* * *$ & 0.096 \\
\hline DC & 0.277 & $* * *$ & 0.134 \\
\hline \multicolumn{4}{|l|}{ Earnings: } \\
\hline Median & $\$ 62,600$ & & $\$ 36,300$ \\
\hline $75^{\text {th }}$ percentile & $\$ 103,800$ & & $\$ 77,500$ \\
\hline \multicolumn{4}{|l|}{ Financial assets: } \\
\hline Median & $\$ 60,500$ & $* * *$ & $\$ 34,000$ \\
\hline $75^{\text {th }}$ percentile & $\$ 223,000$ & $* * *$ & $\$ 174,000$ \\
\hline Sample & 12626 & & 21423 \\
\hline
\end{tabular}

Notes: HRS sample weights. ** and $* * *$ denote that the values are significantly different at the $5 \%$ and $1 \%$ level, adjusted for household level clustering.

Source: Authors' tabulations from the HRS. 
Table 6. Percent of Households Falling Short of Target, Full Sample

\begin{tabular}{lccccccccccc}
\hline \multirow{2}{*}{ Lever } & & \multicolumn{1}{c}{ Age } & & & & & \\
& 60 & 61 & 62 & 63 & 64 & 65 & 66 & 67 & 68 & 69 & 70 \\
\hline Base case & 89.7 & 89.0 & 74.0 & 69.9 & 65.0 & 58.5 & 52.7 & 46.5 & 40.4 & 33.9 & 28.0 \\
With reverse mortgage & 89.7 & 89.0 & 67.2 & 61.8 & 55.2 & 48.2 & 42.1 & 35.9 & 30.4 & 25.3 & 20.4 \\
Control spending & 88.8 & 88.0 & 71.2 & 66.6 & 60.5 & 53.3 & 47.4 & 40.9 & 34.7 & 28.4 & 22.5 \\
All 'riskless equities' & 89.4 & 88.5 & 73.1 & 68.9 & 63.3 & 56.7 & 50.5 & 44.1 & 37.6 & 31.2 & 25.3 \\
\hline
\end{tabular}

Source: Authors' estimates.

Table 7. Wealth by Wealth Deciles, 2008 Dollars

\begin{tabular}{lrr}
\hline \multirow{2}{*}{ Wealth } & \multicolumn{2}{c}{ Financial wealth } \\
\cline { 2 - 3 } & \multicolumn{2}{c}{ Min } \\
\hline Decile 1 & 0 & 400 \\
Decile 2 & 419 & 3,989 \\
Decile 3 & 4,000 & 13,678 \\
Decile 4 & 13,679 & 32,039 \\
Decile 5 & 32,039 & 60,482 \\
Decile 6 & 60,515 & 103,593 \\
Decile 7 & 103,593 & 168,686 \\
Decile 8 & 168,748 & 298,240 \\
Decile 9 & 298,620 & 554,000 \\
Decile 10 & 554,115 & -- \\
\hline
\end{tabular}

Source: Authors' tabulations from the HRS. 
Table 8. Percent of Households Falling Short of Target, Top Wealth Decile

\begin{tabular}{lccccccccccc}
\hline \multirow{2}{*}{ Lever } & \multicolumn{10}{c}{ Age } \\
\cline { 2 - 12 } & 60 & 61 & 62 & 63 & 64 & 65 & 66 & 67 & 68 & 69 & 70 \\
\hline Base case & 56.6 & 54.6 & 38.8 & 34.4 & 29.5 & 24.5 & 20.1 & 17.3 & 14.4 & 11.4 & 8.4 \\
With reverse mortgage & 56.6 & 54.6 & 37.3 & 31.6 & 26.0 & 20.6 & 17.1 & 14.5 & 11.4 & 8.7 & 5.8 \\
Control spending & 54.4 & 51.7 & 36.1 & 30.8 & 25.6 & 20.1 & 17.8 & 14.1 & 11.3 & 8.1 & 5.1 \\
All 'riskless equities' & 56.2 & 53.4 & 37.4 & 32.9 & 26.4 & 21.6 & 18.7 & 13.6 & 10.0 & 7.0 & 4.0 \\
\hline
\end{tabular}

Source: Authors' estimates.

Table 9. Amount Required as Compensation for Retaining Typical Portfolio Allocation, 2008 Dollars

\begin{tabular}{lcc}
\hline $\begin{array}{c}\text { Household type } \\
\text { and risk aversion }\end{array}$ & $\begin{array}{l}\text { Retaining typical portfolio } \\
\text { rather than switching to } \\
\text { optimal portfolio }\end{array}$ & $\begin{array}{l}\text { Retaining typical portfolio } \\
\text { rather than switching to } \\
\text { all-stock portfolio }\end{array}$ \\
\hline Typical household & $\$ 5,600$ & $-\$ 3,600$ \\
CRRA $=5$ & 25,700 & 25,700 \\
CRRA $=2$ & & \\
Top decile household & $\$ 87,000$ & $-\$ 302,700$ \\
CRRA $=5$ & 20,000 & $-11,100$ \\
CRRA $=2$ & & \\
\hline
\end{tabular}

Source: Authors' calculations. 
Table 10. Typical and Optimal Portfolio Allocations, Percentage

\begin{tabular}{lc}
\hline Household type and risk aversion & \\
\hline Typical household & \\
Typical stock allocation & $36 \%$ \\
Optimal stock allocation - CRRA = 5 & 51 \\
Optimal stock allocation - CRRA = 2 & 100 \\
& \\
Top decile household & \\
Typical stock allocation & $57 \%$ \\
Optimal stock allocation - CRRA = 5 & 29 \\
Optimal stock allocation - CRRA = 2 & 70 \\
\hline
\end{tabular}

Note: Optimal stock allocations are calculated at age 65.

Source: Authors' calculations. 


\section{RECENT WORKING PAPERS FROM THE CENTER FOR RETIREMENT RESEARCH AT BOSTON COLLEGE}

Great Recession-Induced Early Claimers: Who Are They? How Much Do They Lose?

Matthew S. Rutledge and Norma B. Coe, April 2012

Effects of Employer Health Costs on the Trend and Distribution of Social Security-Taxable Wages

Gary Burtless And Sveta Milusheva, April 2012

Should Households Base Asset Decumulation Strategies on Required Minimum

Distribution Tables?

Wei Sun and Anthony Webb, April 2012

Geographic Mobility Among Residents in Seniors Housing and Care Communities:

Evidence from the Residents Financial Survey

Norma B. Coe and April Yanyuan Wu, April 2012

Costs and Concerns Among Residents in Seniors Housing and Care Communities:

Evidence from the Residents Financial Survey

Norma B. Coe and April Yanyuan Wu, April 2012

Financial Well-Being of Residents in Seniors Housing and Care Communities: Evidence from the Residents Financial Survey

Norma B. Coe and April Yanyuan Wu, April 2012

Residents in Senior Housing and Care Communities: Overview of the Residents Financial Survey

Norma B. Coe and April Yanyuan Wu, April 2012

Social Security Claiming: Trends and Business Cycle Effects

Owen Haaga and Richard W. Johnson, February 2012

Economic Consequences of the Great Recession: Evidence from the Panel Study of Income Dynamics

Barry Bosworth, February 2012

The Changing Causes and Consequences of Not Working Before Age 62

Barbara A. Butrica and Nadia Karamcheva, February 2012

The Impact of Temporary Assistance Programs on Disability Rolls and Re-Employment Stephan Lindner and Austin Nichols, January 2012

All working papers are available on the Center for Retirement Research website (http://crr.bc.edu) and can be requested by e-mail (crr@bc.edu) or phone (617-552-1762). 